\title{
Impactos da metropolização no sistema de transporte coletivo: estudo de caso na Região Metropolitana de Goiânia
}

\author{
Impacts of metropolization on mass transit: \\ a case study in the Metropolitan Region of Goiânia
}

Ana Carolina Fernandes Pires [I]

Érika Cristine Kneib [II]

Rômulo José da Costa Ribeiro [III]

\section{Resumo}

0 processo de urbanização ao qual estão submetidas as regiões metropolitanas brasileiras ocorre de forma insustentável. Intensa polarização e dependência entre seus municípios propicia deslocamentos pendulares, realizados geralmente por ônibus coletivos, que circulam com baixa rotatividade de passageiros em extensos vazios urbanos. Esta pesquisa apresenta os impactos que a metropolização provoca no sistema de transporte coletivo, com estudo de caso em municípios selecionados da Região Metropolitana de Goiânia (RMG). Indicadores de qualidade e eficiência são utilizados para a avaliação do sistema de transporte coletivo. Os resultados demonstram impactos econômicos no sistema de transporte coletivo e impactos sociais para os passageiros. A conclusão deste trabalho demonstra necessidade de descentralização das atividades socioeconômicas na RMG e políticas para potencialização do transporte coletivo.

Palavras-chave: relações metropolitanas; deslocamento pendular; espraiamento urbano; transporte coletivo; Região Metropolitana de Goiânia.

\begin{abstract}
The urbanization process of the Brazilian metropolitan regions has not been sustainable. Intense conurbation and dependence among its municipalities foster intermunicipal commuting, usually through mass transit buses, which circulate with low passenger turnover, regularly traversing urban voids. This research presents the impacts that metropolization causes on mass transit, through a case study conducted at selected municipalities in the Metropolitan Region of Goiânia (MRG). Quality and efficiency indicators are used to evaluate the mass transit system. The results demonstrate economic impacts on mass transit and social impacts for passengers. The conclusion of this work shows that it is necessary to decentralize the socio-economic activities in the MRG and to make policies to promote mass transit.
\end{abstract}

Keywords: metropolitan relations; commuting; urban sprawl; mass transit; Metropolitan Region of Goiânia. 


\section{Introdução}

As cidades nunca abrigaram tantas pessoas como se observa atualmente. 0 crescimento da população urbana aumentou consideravelmente nas últimas décadas, passando de 200 milhões para mais de 2 bilhões de habitantes entre as décadas de 1950 e 1980, de acordo com Rogers e Gumuchdjian (2005). A previsão, segundo a United Nations (2015), é de que população humana urbana cresça de $54 \%$ para 66\% entre 2014 e 2050. Esse aumento tem ocorrido principalmente nos países em desenvolvimento, que abrigarão cerca de 2,2 bilhões de novos habitantes entre 2015 e 2050. A forma como esses novos habitantes serão acomodados no território tem impactos ambientais, sociais e econômicos.

No Brasil, o crescimento das cidades não tem ocorrido de forma sustentável. A rápida e intensa urbanização promoveu relações de interdependência entre as cidades, em que os limites municipais não correspondem aos limites das relações sociais, econômicas e culturais (Ministério das Cidades, 2015). Como esclarece o Instituto de Pesquisa Econômica Aplicada (Ipea, 2010), esse processo é denominado metropolização e é caracterizado pela forma de expansão centro/periferia das cidades, em que a cidade polo ou cidade-núcleo concentra investimentos, oportunidades de trabalho, serviços de saúde e educação, enquanto grande parte da população mora em periferias distantes, completamente desprovidas de oportunidades e urbanidade.

O descompasso entre os locais de trabalho/estudo e os locais de moradia gera o deslocamento pendular (Cunha, 2006) direcionado ao município-sede, uma vez que este se torna um polo de atração de viagens. Como a maior parte dos deslocamentos é atendida por ônibus urbanos, e estes precisam circular por extensos vazios urbanos, sem prioridade nas vias e infraestrutura adequada, o transporte coletivo fica sujeito ao alto tempo de viagem e congestionamentos. Tais questões, relacionadas à distância, contribuem para a perda da qualidade e eficiência do sistema de transporte coletivo (Ministério das Cidades, 2015; Ferraz e Torres, 2004).

A mobilidade da população no interior dos municípios periféricos das regiões metropolitanas, por sua vez, é caracterizada pela falta de infraestrutura, disponibilidade de recursos e oferta de modais que possam satisfazer a necessidade da população local (Ministério das Cidades, 2015), situação esta que se relaciona diretamente com a forma de ocupação urbana em tais municípios: dispersa e fragmentada, realizada prioritariamente com o objetivo de integração com a capital.

Exemplo de tal situação acontece na Região Metropolitana de Goiânia (RMG), localizada no estado de Goiás. De acordo com dados do Instituto Brasileiro de Geografia e Estatística (IBGE, 2010), o crescimento da população na região tem acontecido, principalmente, por meio dos municípios do entorno. No entanto, as migrações para RMG acontecem a partir da atração exercida por Goiânia, de forma que as pessoas se instalam nos municípios do entorno, mas buscam trabalho, educação e saúde na capital.

Os deslocamentos pendulares advindos de tal dicotomia são caracterizados por altos tempos de viagem entre os municípios da RMG, prioritariamente em direção à capital, segundo dados do IBGE (2016). Esses deslocamentos são diários, realizados principalmente por ônibus, e representam a dependência da 
população principalmente em relação à oferta de estudo e trabalho na capital.

A compreensão de que as relações metropolitanas no Brasil são estruturantes do território que abrange mais de um município propiciou a criação do Estatuto das Metrópoles, lei federal aprovada em janeiro de 2015 e que estabelece conceitos, fundamentos, diretrizes e instrumentos para a gestão compartilhada de regiões metropolitanas. Essa lei instituiu a chamada governança interfederativa, a qual permite o compartilhamento das responsabilidades e ações entre entes federativos no que se refere a organização, planejamento e execução de funções públicas de interesse comum; e também o instrumento de planejamento denominado Plano de Desenvolvimento Urbano Integrado, o qual permite a elaboração de diretrizes para o planejamento integrado de desenvolvimento de regiões metropolitanas ou aglomerações urbanas (Brasil, 2015, art. 20, IV e VI).

Considerando as possibilidades advindas do Estatuto da Metrópole e diante do cenário dicotômico de oportunidades e urbanidade nas regiões metropolitanas, a utilização desse instrumento legal é de extrema importância, assim como os estudos que visam a subsidiar sua aplicação. Nesse contexto, a indagação que conduz esta pesquisa é: como as relações metropolitanas impactam o sistema de transporte público coletivo? Para subsidiar essa investigação, esta pesquisa é fundamentada em um estudo de caso na Região Metropolitana de Goiânia (RMG).

Este trabalho é estruturado em cinco partes. Após a introdução, o referencial teórico apresenta a revisão bibliográfica necessária ao entendimento do procedimento proposto para a investigação do problema anteriormente citado. Posteriormente, em A Região Metropolitana de Goiânia, são apresentadas as informações mais relevantes para a compreensão da dinâmica metropolitana na Região Metropolitana de Goiânia. A construção da metodologia de análise é apresentada no item denominado procedimento de análise, assim como também o são sua aplicação na região de estudo e análise. Finalmente, as principais reflexões sobre o trabalho são apresentadas nas considerações finais.

\section{Referencial teórico}

\section{Relações metropolitanas}

Segundo Villaça (1997), o processo de crescimento de algumas cidades pode absorver ou englobar áreas urbanas ao seu redor. Em alguns casos, essas áreas urbanas estão localizadas em outras unidades administrativas (municípios), o que caracteriza uma forma de urbanização distinta, um tipo de cidade "particular", em que os limites municipais não são apropriados para delimitar as relações urbanas. $\mathrm{O}$ autor denomina esse tipo de cidade como área metropolitana.

Conforme esclarece o Ipea (2010), essas cidades em ampliação concentram investimentos, atividades, poder e pessoas, comandando um território que ultrapassa seus limites administrativos. Enquanto isso, grande parte da população se instala em áreas periféricas distantes, em espaços desprovidos de condições mínimas de infraestrutura e urbanidade, completamente distintos da cidade-núcleo.

Tal espaço segregado é tecido por diferentes agentes, prioritariamente em função da 
lógica imobiliária, que se materializa em ações estatais, com concentração de investimentos em áreas centrais consolidadas, encarecendo o preço do solo, e com ações do próprio setor imobiliário, que retém terrenos em regiões já providas de infraestrutura, com objetivo de valorizá-los. De acordo com o Instituto Mauro Borges de Estatísticas e Estudos Socioeconômicos (IMB, 2012), as áreas periféricas da cidade são ocupadas por segmentos populacionais de baixa renda que procuram terrenos mais acessíveis economicamente e que são viabilizados, muitas vezes, pelas políticas públicas de habitação popular que desconsideram a falta de infraestrutura e os serviços básicos nessas áreas.

No entanto, não se pode desconsiderar a crescente parcela da população com altos rendimentos que procura residir na periferia em busca de níveis de vida mais elevados, ocupando os condomínios horizontais (ibid.). A viabilização de novos empreendimentos habitacionais é resultado da sinergia entre proprietários de glebas e empresas imobiliárias e acontece de maneira desassociada das indicações dos planos diretores municipais. Posteriormente, os governos municipais redefinem o arcabouço legislativo para que as ações do setor privado sejam legitimadas (Bitoun e Souza, 2015).

Nas periferias citadas, a forma de urbanização tem ocorrido de forma dispersa no território, seguindo uma lógica de urbanização com baixa densidade e sem continuidade em função da falta de planejamento e da concentração de investimentos em serviços e infraestruturas destinadas ao automóvel (Balbim, 2016).

0 descompasso entre os locais de trabalho/estudo e os locais de moradia gera o deslocamento pendular (Cunha, 2006) que pode ser definido como o deslocamento que um conjunto de pessoas realiza entre a unidade espacial em que se localiza sua residência e a unidade espacial onde trabalha ou estuda. Cunha (ibid.) chama a atenção para o fato de que os deslocamentos pendulares podem introduzir novas formas de riscos e carências para os indivíduos, como o aumento de tempo no deslocamento, a diminuição das horas de descanso e lazer, riscos decorrentes do uso dos meios de transportes em si, entre outros.

A presença de rodovias nas metrópoles favorece o fluxo de pessoas e cargas pelo modo motorizado individual e reduz a importância das distâncias, o que favorece a expansão e a articulação espacial das aglomerações. Mattos (2004), ao tratar das rodovias, afirma que estas contribuem para afirmar nas metrópoles a morfologia do tipo tentacular e fortalecem a tendência a uma metropolização expandida ou dilatada.

\section{Mobilidade metropolitana}

A partir de 2012, a mobilidade urbana passou a ser definida, no Brasil, pela lei que regula a Política de Mobilidade Urbana no País, segundo a qual mobilidade urbana se define como "condição em que se realizam os deslocamentos de pessoas e cargas no espaço urbano" (Brasil, 2012, art. 4으. II). Para compreender tais deslocamentos, é preciso considerar que a mobilidade está fortemente relacionada aos processos de urbanização, caracterizando-se como um processo socioespacial que se particulariza em função da formação de cada lugar (Ipea, 2016).

Nesse sentido, a expansão das aglomerações urbanas, cuja lógica se dá em função da localização dos locais de emprego no núcleo 
das aglomerações e da localização das moradias em áreas periféricas, propicia o deslocamento pendular, considerado um dos traços mais marcantes da nova ordem mundial. Cada vez mais trabalhadores abrigam-se nas áreas periféricas e contribuem para sua ampliação (IBGE, 2016).

Dados do Censo demográfico de 2010 mostram que o número de pessoas que se deslocam para trabalhar em município diferente do município de residência, cotidianamente, cresceu na última década. Segundo o Censo, em 2010, 15.472.863 pessoas saíam do município de suas residências para trabalhar e estudar, ou ambos, em outro município, caracterizando fluxos de origem (saída), como pode ser observado na Tabela 1. Em 2000, o número de deslocamentos relativos ao fluxo de saída era de 7.403.456 pessoas; esse valor recebeu um incremento de 8.069.407 pessoas em 2010.

Os fluxos de destino (chegada), em 2000, correspondiam a 7.030 .250 pessoas, valor que aumentou para 13.946.545 em 2010. Apesar de os deslocamentos estarem distribuídos pelo País, esse processo está fundamentalmente associado à expansão das aglomerações urbanas, principalmente as de caráter metropolitano, e à possibilidade de usar o transporte público ou particular.

Em todas as regiões metropolitanas, 0 fluxo mais importante é aquele cuja origem está nos municípios periféricos em direção ao município-polo. Segundo Delgado et al. (2016), fluxos maiores indicam maior processo de periferização da ocupação e maior concentração de atividades no município-polo. Como pode ser observado na Tabela 2, com exceção de Salvador (29,3\%) e Manaus (22,9\%), todas as regiões apresentam mais de $50 \%$ dos deslocamentos pendulares na direção periferia-polo. A Região Metropolitana de Goiânia destaca-se nesse contexto, apresentando o segundo maior percentual de fluxo pendular periferia-polo dentre as regiões metropolitanas brasileiras.

Tabela 1 - População que estuda e que realiza movimento pendular, segundo direção dos fluxos - Brasil (2010)

\begin{tabular}{|c|c|c|c|c|c|}
\hline \multirow{3}{*}{$\begin{array}{l}\text { Tamanho } \\
\text { dos fluxos }\end{array}$} & \multirow{3}{*}{$\begin{array}{c}\begin{array}{c}\text { População que estuda } \\
\text { e/ou trabalha }\end{array} \\
\text { Número } \\
\text { de pessoas }\end{array}$} & \multicolumn{4}{|c|}{ Movimento pendular } \\
\hline & & \multicolumn{2}{|c|}{ Entradas } & \multicolumn{2}{|c|}{ Saídas } \\
\hline & & $\begin{array}{l}\text { Número } \\
\text { de pessoas }\end{array}$ & $\begin{array}{c}\text { Participação } \\
\text { (\%) }\end{array}$ & $\begin{array}{l}\text { Número } \\
\text { de pessoas }\end{array}$ & $\begin{array}{c}\text { Participação } \\
\text { (\%) }\end{array}$ \\
\hline 2000 & 109.822 .011 & 7.030 .250 & 6,4 & 7.403 .456 & 6,7 \\
\hline 2010 & 145.919 .020 & 13.946 .545 & 9,6 & 15.472 .863 & 10,6 \\
\hline Variação (\%) & 32,9 & 98,4 & - & 109 & - \\
\hline
\end{tabular}

Fonte: IBGE (2010). Adaptado pela autora. 
Tabela 2 - Distribuição percentual dos deslocamentos pendulares segundo o tipo de fluxo (2010)

\begin{tabular}{l|c|c|c|c|c|c}
\hline \multirow{2}{*}{$\begin{array}{l}\text { Região } \\
\text { Metropolitana }\end{array}$} & \multicolumn{7}{c}{ Tipo de fluxo pendular } \\
\cline { 2 - 7 } & $\begin{array}{c}\text { Periferia/ } \\
\text { Polo }\end{array}$ & $\begin{array}{c}\text { Periferia/ } \\
\text { Periferia }\end{array}$ & $\begin{array}{c}\text { Polo/ } \\
\text { Periferia }\end{array}$ & Outra RM & Fora da RM & Total \\
\hline Manaus & 22,9 & 3,0 & 19,1 & 1,3 & 53,6 & 100,0 \\
Belém & 66,6 & 9,1 & 8,9 & 1,3 & 14,0 & 100,0 \\
Fortaleza & 58,2 & 17,9 & 13,1 & 1,4 & 9,4 & 100,0 \\
Recife & 63,2 & 19,9 & 9,8 & 0,6 & 6,5 & 100,0 \\
Salvador & 29,3 & 23,5 & 30,9 & 4,1 & 12,3 & 100,0 \\
Belo Horizonte & 62,4 & 21,3 & 11,7 & 0,8 & 3,8 & 100,0 \\
Rio de Janeiro & 61,4 & 29,1 & 4,7 & 0,9 & 4,0 & 100,0 \\
São Paulo & 50,9 & 35,5 & 8,6 & 0,5 & 4,5 & 100,0 \\
Curitiba & 66,0 & 13,2 & 15,4 & 1,1 & 4,4 & 100,0 \\
Porto Alegre & 52,0 & 36,8 & 6,2 & 0,5 & 4,5 & 100,0 \\
Goiânia & 78,1 & 2,8 & 8,1 & 3,2 & 7,8 & 100,0 \\
Ride DF & 85,5 & 4,2 & 4,3 & 2,1 & 3,9 & 100,0 \\
\hline Total & 58,5 & 26,3 & 9,1 & 1,0 & 5,3 & 100,0 \\
\hline
\end{tabular}

Fonte: IBGE (2010). Adaptado pela autora.

A magnitude dos deslocamentos pendulares com fluxo periferia-polo revela a dependência da mobilidade para o acesso a mercado de trabalho, serviços e atividades de educação, que se distribuem de forma desigual entre municípios de uma mesma região. Nesse sentido, a mobilidade urbana tem papel cada vez mais destacado nas condições de vida da população: a inclusão dos serviços de transporte nas despesas familiares compromete $20 \%$ da renda familiar (Barbosa, 2016).

\section{Qualidade e eficiência em transporte coletivo}

A qualidade no sistema de transporte coletivo concentra-se nos aspectos que influenciam diretamente a percepção do usuário em uma viagem (Transportation Research Board - TRB, 2013 , p. 149). A qualidade mede a disponibilidade, o conforto, as facilidades oferecidas e depende, muitas vezes, das decisões operacionais tomadas no sistema de transporte coletivo a respeito das características do serviço que vai ser oferecido, como esclarece a Associação Nacional das Empresas de Transportes Urbanos (NTU, 2008).

Ferraz e Torres (2004) e NTU (2008) apresentam os principais fatores de qualidade para o transporte coletivo por ônibus: acessibilidade, frequência de atendimento, tempo de viagem, lotação, confiabilidade, segurança, características dos ônibus, características dos locais de parada, sistema de informações, conectividade, comportamento dos operadores e estado das vias. 
A eficiência, por sua vez, relaciona-se diretamente ao desempenho do serviço ofertado. Para Ferraz e Torres (2004), a eficiência, relacionada à área econômica, refere-se à produtividade e expressa a relação entre o produto obtido e os insumos gastos na produção. 0 produto obtido é a viagem ofertada, enquanto os insumos são os veículos, funcionários, combustível, pneus, peças, acessórios, lubrificantes, etc. Maior eficiência econômica significa alcançar um custo final menor, para um determinado padrão de qualidade ou de serviço. A eficiência econômica é avaliada a partir do custo por passageiro transportado.

De forma geral, para que a eficiência seja máxima, é importante que: a distância a ser percorrida seja reduzida ao mínimo possível, para que a quilometragem percorrida e o número de veículos utilizados sejam menores e, assim, haja menos gastos com combustível, lubrificantes, pneus, peças e acessórios, salários e encargos sociais de operadores, etc.; a velocidade utilizada seja a máxima possível, para a redução do tempo de viagem e a consequente diminuição no número de veículos e gastos correspondentes; a capacidade dos veículos seja a máxima possível, de acordo com a demanda de passageiros e a geometria da via, para a redução da quilometragem rodada e do número de veículos empregados, com a consequente redução dos gastos relacionados aos veículos (ibid.).

Para caracterizar os impactos sociais e econômicos provocados pelas relações metropolitanas e dispersão urbana no sistema de transporte coletivo, são utilizados, nesta pesquisa, alguns indicadores de eficiência e qualidade, conforme descrição do procedimento metodológico no item Procedimento de Análise. Estes indicadores são compostos por variáveis que se relacionam às relações metropolitanas (referem-se aos deslocamentos pendulares) e à dispersão urbana nos municípios periféricos, e que necessitam de dados que são viáveis e disponíveis para seu cálculo e análise. A partir dessas questões, os indicadores selecionados são:

- Indicadores de qualidade: a) Intervalo de viagens, que representa intervalo de tempo entre duas paradas de veículo para embarque e desembarque de passageiros (Vuchic, 2004); b) tempo de viagem: representa o tempo de ida e volta entre terminais ou pontos iniciais e finais (Ferraz e Torres, 2004).

- Indicadores de eficiência: a) número de passageiros por quilômetro (quilometragem operacional), conhecido como IPK (Índice de Passageiros por Km) (NTU, 2008); refere-se à "relação entre a quantidade de passageiros transportados e o número de quilômetros percorridos" (Ferraz e Torres, 2004, p. 122). Esse índice permite averiguar o grau de utilização do serviço de transporte coletivo por ônibus na cidade, a eficiência do serviço (relacionada ao planejamento físico da rede e à programação operacional) e as características de uso e ocupação do solo. De acordo com a NTU (2008), o IPK representa a rotatividade dos passageiros no ônibus. Quando os valores são baixos, a renovação de passageiros é baixa, o que é típico de movimentos pendulares em linhas com percursos grandes, nos quais a maioria dos passageiros percorre grandes distâncias, entrando no ponto inicial e descendo no ponto final; b) Número de passageiros por veículo (frota operacional), que corresponde à "relação entre a quantidade de passageiros transportados por dia e o número de veículos" (Ferraz e Torres, 2004, p. 122). Tal índice reflete a eficiência do serviço (planejamento da 
Tabela 3 - Padrões de qualidade para o transporte público por ônibus

\begin{tabular}{l|c|c|c|c}
\hline \multicolumn{1}{c|}{ Fatores } & Parâmetros de avaliação & Bom & Regular & Ruim \\
\hline Intervalo de Viagem & $\begin{array}{c}\text { Intervalo entre atendimentos } \\
\text { (minutos) }\end{array}$ & $<15$ & $15-30$ & $15-30$ \\
Tempo de Viagem & $\begin{array}{c}\text { Relação entre o tempo de viagem por } \\
\text { onibus e por carro }\end{array}$ & $<1,5$ & $1,5-2,5$ & $1,5-2,5$ \\
\hline
\end{tabular}

Fonte: Ferraz e Torres (2004). Adaptado pela autora.

Tabela 4 - Valores mínimos/máximos considerados satisfatórios para alguns dos índices de eficiência econômica

\begin{tabular}{l|c}
\multicolumn{1}{c|}{ Índices de eficiência } & Valores máximos/mínimos \\
\hline Índice de passageiros por veículo (pass./veíc./dia) & $>500$ \\
Índice de passageiros por quilômetro (pass./km) & $>2,5$ \\
\hline
\end{tabular}

Fonte: Ferraz e Torres (2004). Adaptado pela autora.

rede de rotas e programação da operação), o grau de utilização do serviço e características de uso e ocupação do solo.

A partir dos indicadores escolhidos, são utilizados os padrões propostos pelos autores (Tabelas 3 e 4) que permitem a classificação ou avaliação, a partir de uma medida-síntese, dos fenômenos que podem impactar o transporte coletivo.

\section{A Região Metropolitana de Goiânia}

\section{Aspectos gerais}

A Região Metropolitana de Goiânia (RMG) foi instituída pela lei complementar estadual n. 27 de 1999 e, atualmente, apresenta a constituição estabelecida e alterada pela lei complementar n. 78, de 2010, a qual estabelece que a RMG é constituída por 20 municípios, conforme apresenta a Figura 1 (Goiás, 2000, 2010).

A RMG possui 2.173.141 habitantes distribuídos em $7.315 \mathrm{~km}^{2}$, com densidade demográfica de 297,07 hab./km². Em 2010, possuía um grau de urbanização de $98 \%$ e 1/3 da população estadual residia na RM. A população de Goiânia, município-núcleo da RM, correspondia, em 2010, a 60\% da população metropolitana, segundo o Programa das Nações Unidas para o Desenvolvimento (Pnud, 2014).

A análise da densidade populacional na RMG permite identificar os locais de moradia da população metropolitana. Os dados do IBGE (2010) demonstram que a maior concentração de pessoas na RMG, em 2010, residia no 
Figura 1 - Região Metropolitana de Goiânia:

alterações na composição dos municípios, 1999-2010

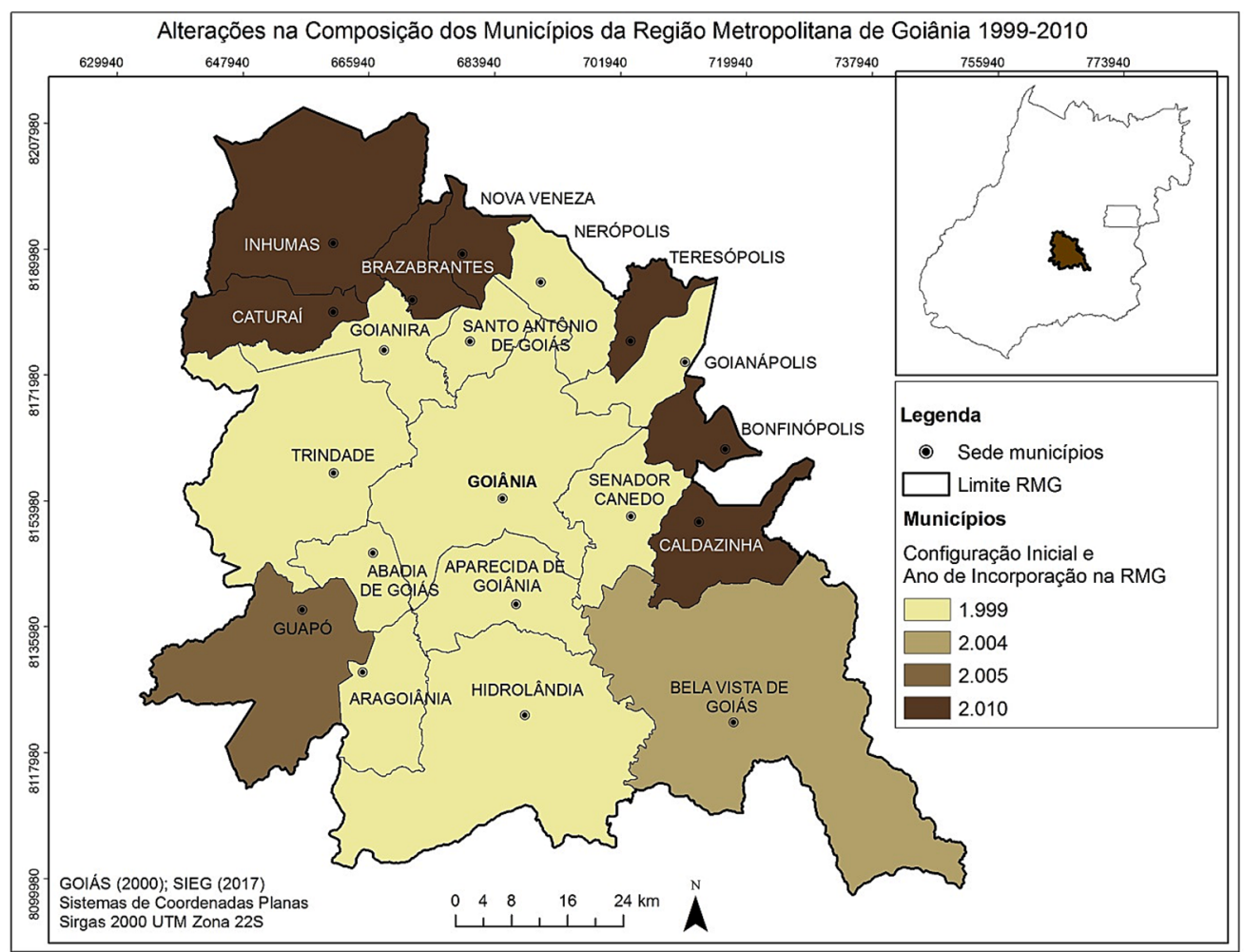

Fonte: Goiás (2000); Sistema Estadual de Geoinformação de Goiás (Sieg, 2017). Elaborado pela autora.

município de Goiânia, cuja densidade demográfica atingiu 1.776,74 hab./km². No entanto, os municípios do entorno apresentaram taxas de crescimento geométrico populacionais maiores que o município-polo, dentre os quais se destacam Goianira (6,17\%), Senador Canedo (4,75\%) e Santo Antônio de Goiás (4,24\%).

A análise da população estimada para 2017 (IMB, 2017) mostra que o núcleo urbano da RMG continua crescendo, mas com taxas pequenas em relação à periferia, que continua crescendo mais que Goiânia, embora com menor intensidade que em 2010. As maiores taxas são observadas nos mesmos municípios destacados em 2010: Senador Canedo $(3,23 \%)$, Santo Antônio de Goiás $(3,01)$ e Goianira (2,75).

A maior concentração de empregos formais (emp./hab.) na RMG, em contrapartida aos locais de incremento populacional, localiza-se no núcleo urbano (Goiânia). Goiânia e Santo Antônio de Goiás, em 2016, foram os 
dois municípios com maiores números de empregos formais por habitante, 0,40 emp./hab. e 0,34 emp./hab., respectivamente. Em números, a maior quantidade de empregos estava localizada em Goiânia (581.541 empregos formais ou $76,47 \%$ do total de empregos na RMG) e Aparecida de Goiânia (105.707empregos ou $13,90 \%$ do total de empregos na RMG), segundo dados do IBGE (2017) e do Ministério do Trabalho (2017).
Como abordado por Cunha (2006), esse descompasso entre os locais de moradia e emprego gera os deslocamentos pendulares. O fluxo de deslocamentos pendulares entre os municípios da RMG em 2010 está representado na Figura 2. É possível observar que os maiores fluxos existem entre os municípios Aparecida de Goiânia, Senador Canedo, Trindade e o município Goiânia, que são também os municípios com maiores números de empregos formais.

Figura 2 - Fluxos pendulares por motivo de trabalho e/ou estudo nos municípios da RMG

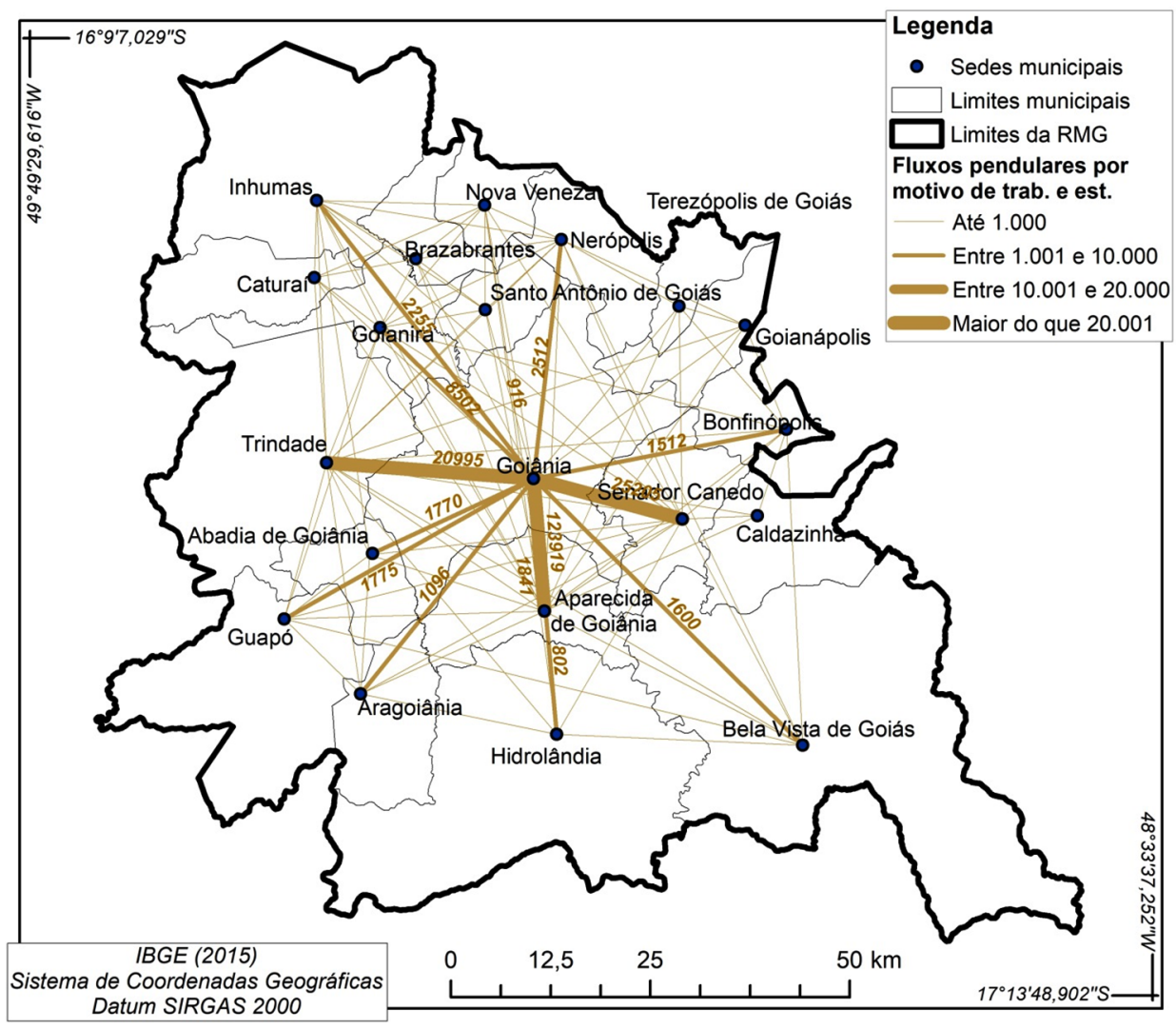

Fonte: UFG (2017). 
Dados do IBGE (2016) demonstram que Aparecida de Goiânia é o município de origem do maior fluxo de pessoas que vão diariamente para Goiânia: das 176.112 pessoas que vão para capital trabalhar ou estudar, 110.378 são de Aparecida de Goiânia, o que corresponde a $62,67 \%$ do total. Senador Canedo com 13,51\%, Trindade com 10,45\% e Goianira com 4,59\% do total também são municípios de origem com fluxo importante para Goiânia. Esses municípios são limítrofes à capital e com ela conurbados ou em processo de conurbação. Os quatros municípios, juntos, são responsáveis por $91,22 \%$ do total de deslocamentos pendulares com destino a Goiânia.

Apesar de os dados analisados serem de 2010, é possível confirmar a alta demanda por viagens pendulares com destino a Goiânia por meio do número de passageiros catracados no Sistema de Transporte Coletivo da RMG em maio de 2017 nas linhas que realizam a ligação dos municípios periféricos com Goiânia a partir de dados disponibilizados pela Companhia Metropolitana de Transporte Coletivo (CMTC, 2017). Os dados referentes aos passageiros catracados são apresentados no item a seguir, após breve explicação sobre a rede de transporte coletivo que serve a RMG.

\section{A rede metropolitana de transporte coletivo}

O sistema de transporte público da RMG é estruturado pela Rede Metropolitana de Transportes Coletivos (RMTC), que atende 18 municípios da Região Metropolitana de Goiânia. Tal rede é formada por 309 linhas de ônibus (CMTC, 2017), estruturada por meio de 21 terminais de integração e aproximadamente
6.000 pontos de ônibus, os quais distam no máximo 1000 metros de qualquer residência (RMTC, 2017).

A gestão da RMTC é realizada pela Companhia Metropolitana de Transportes Coletivos (CMTC), uma empresa pública que, além de ostentar o papel institucional de braço executivo da CDTC-RMG, também é responsável, dentre outras atribuições, pelo gerenciamento, o controle e a fiscalização tanto da operação como da infraestrutura do serviço. Já os serviços ofertados e produzidos pela RMTC são realizados pelas concessionárias Rápido Araguaia Ltda., HP Transportes Coletivos Ltda., Viação Reunidas Ltda., Cootego (Cooperativa de Transportes do Estado de Goiás) e a estatal Metrobus Transporte Coletivo S.A. (CMTC, 2013).

A Figura 3 apresenta os terminais da RMTC sobre a mancha urbana da Região Metropolitana de Goiânia. Em destaque, estão as linhas de interesse metropolitano, por onde transitam os ônibus que fazem o percurso entre municípios distintos. Ligando os terminais de Senador Canedo, Goianira, Trindade e Goiânia, estão representadas as linhas que compõem o Eixo Anhanguera. A integração pelo Eixo Anhanguera começou em 2014. Os usuários das linhas integrantes no eixo passaram a receber subsídio do governo estadual, o que aumentou muito a demanda por essas linhas.

Segundo dados da CMTC, foram catracados 90.247 passageiros mensais na linha que sai do terminal Trindade com destino ao terminal Padre Pelágio, em Goiânia; 168.651 passageiros mensais na linha que sai do terminal Goianira com destino ao terminal Padre Pelágio, em Goiânia; 203.466 passageiros mensais em linhas distintas que saem do terminal de Senador Canedo, com destino ao terminal 
Figura 3 - Linhas de interesse metropolitano e terminais da RMTC

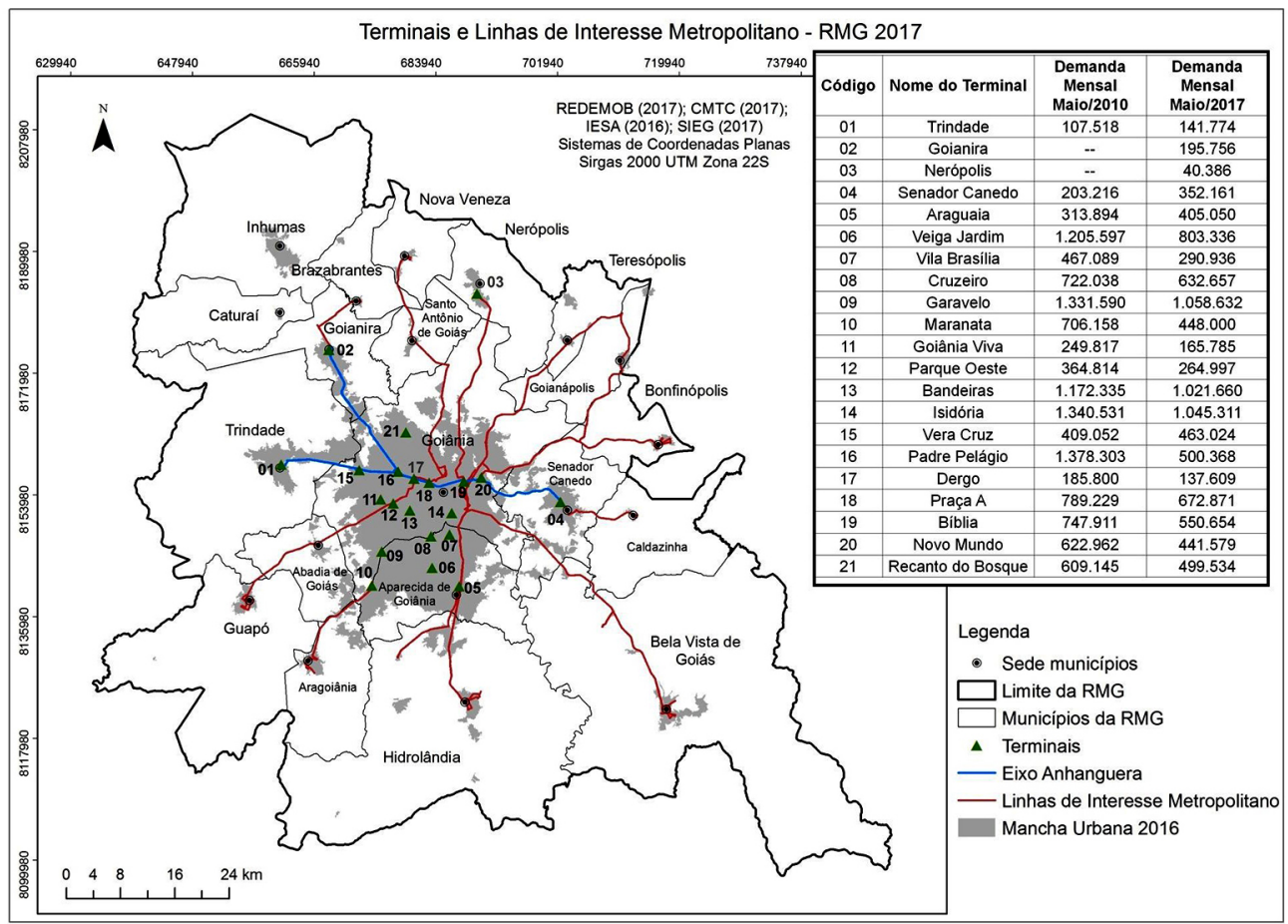

Fonte: lesa (2016); CMTC (2017); Redemob (2017); Sieg (2017). Elaborado pela autora.

praça da Bíblia, em Goiânia. Os passageiros catracados que saem de Aparecida de Goiânia para Goiânia não foram contabilizados em função da complexidade e da quantidade de linhas entre os dois municípios.

É importante destacar que, na RMG, a tarifa para a realização de qualquer deslocamento é única e integrada, fato pioneiro no Brasil (RMTC, 2017). Isso significa que os deslocamentos entre os municípios da RMG custam o mesmo preço dos deslocamentos dentro do município de Goiânia, o que contribui para o aumento dos deslocamentos pendulares na região. 


\section{Procedimento de análise}

\section{Descrição}

O presente trabalho propõe a identificação dos impactos sociais e econômicos que as relações metropolitanas entre municípios provocam no sistema de transporte coletivo, principalmente em função dos deslocamentos pendulares e do espraiamento urbano nos municípios periféricos. Para isso, é realizada uma análise de tal sistema em duas datas distintas, 2010 e 2017, nas quais o sistema apresenta configurações espaciais e operacionais diferenciadas para atender à demanda que varia segundo a ocupação urbana.

É proposta uma comparação quantitativa e qualitativa dos resultados de índices de qualidade e eficiência que se relacionam às características do crescimento urbano na RMG e os consequentes deslocamentos pendulares. Tais índices são utilizados para a aferição desses impactos no transporte coletivo nas linhas de ônibus que atendem cada município selecionado, e, posteriormente, uma análise geral comparativa permite identificar as semeIhanças e divergências dos impactos identificados entre esses municípios, possibilitando a compreensão das relações entre a forma das ocupações urbanas e a rede de transporte coletivo na RMG.

A escolha dos municípios que são analisados ocorreu em função dos seguintes critérios: a) municípios que apresentaram número expressivo de deslocamentos pendulares em direção a Goiânia em 2010, segundo dados do IBGE (2016); b) municípios em que houve expansão urbana entre 2010 e 2016 (datas em que a mancha urbana da RMG foi georreferenciada), identificada por meio de dados do Sieg (2016b) e lesa (2016); c) municípios que são atendidos pela RMTC e nos quais houve mudanças na configuração espacial da rede de rotas do transporte coletivo entre 2010 e 2017 (datas em que os dados da RMTC foram disponibilizados), identificadas por meio de dados georreferenciados da Redemob (2017). Dentre os municípios constituintes da RMG, os que atenderam aos critérios propostos e foram selecionados para a análise são: Trindade, Senador Canedo e Goianira.

Para a avaliação dos impactos sociais, propõe-se a utilização de indicadores de qualidade do sistema, relacionados à quilometragem percorrida, levando em consideração que a qualidade reflete a percepção do usuário a respeito do desempenho do sistema de transporte coletivo. Dentre os indicadores propostos por Ferraz e Torres (2004) e pela NTU (2008), aqueles que podem refletir a relação entre a expansão urbana, a polaridade entre municípios e a qualidade do sistema são: o intervalo de viagem e o tempo de viagem.

Os índices utilizados para a avaliação dos impactos sociais foram expostos na Tabela 3, com os respectivos parâmetros de avaliação. 0 Tempo de Viagem, por sua vez, não é aplicado neste trabalho da forma como é proposto por Ferraz e Torres (2004) e NTU (2008), pois não foi possível identificar o Tempo de Viagem dos automóveis no ano 2010. Nas análises propostas neste trabalho, o Tempo de Viagem é caracterizado somente pelo tempo correspondente à duração de uma viagem e é utilizado para comparação dos valores apresentados entre 2010 e 2017 e compreensão da relação entre a variação desses valores e a variação da forma da ocupação urbana na RMG entre 2010 e 2016. 
Na Região Metropolitana de Goiânia, o Intervalo de Viagens e o Tempo de Viagem são referentes ao dia útil e ao horário de pico de viagens do período matutino, o qual acontece entre 05:00 e 07:00 da manhã nos municípios periféricos, segundo a CMTC (2017). O horário de pico é utilizado em função da maior demanda de passageiros nesse horário, ou seja, é o horário em que mais usuários dependem do sistema.

Para a avaliação dos impactos econômicos, propõe-se a utilização de índices de eficiência econômica do sistema, relacionados à quilometragem percorrida e à rotatividade de passageiros, levando-se em consideração que a distância é um dos três fatores principais destacados por Ferraz e Torres (2004) capazes de alterar a eficiência econômica do sistema de transporte coletivo, e que a rotatividade de passageiros é essencial para a viabilização do serviço oferecido. Os índices que podem refletir a relação entre a expansão urbana, as relações metropolitanas e a eficiência econômica do sistema são: o Índice de Passageiro por Quilômetro (pass./veíc.) e o Índice de Passageiros por Veículo (pass./veíc/dia). Os índices utilizados para a avaliação dos impactos econômicos estão expostos na Tabela 4, com os respectivos parâmetros de avaliação.

\section{Aplicação do procedimento}

Para melhor compreensão, primeiramente, é exposto um mapa com as linhas de ônibus de cada município nos anos 2010 e 2017. É importante destacar que as linhas existentes em 2010 estão sobrepostas às linhas de 2017 nesses mapas, de forma que seja possível compreender que as linhas existentes em 2017 são extensões e/ou alterações daquelas existentes em 2010. Em seguida, são expostas tabelas com o resultado da aplicação dos indicadores. Nas tabelas, as linhas são classificadas por tipo, como demonstrado a seguir:

- Linhas de Ligação: linhas que ligam um município a Goiânia por meio de terminais;

- Linhas Expressas: linhas que ligam um município a Goiânia sem terminais;

- Linhas Alimentadoras: linhas que distribuem as viagens no interior do município, com ponto de partida em terminais;

- Linhas de Conexão: linhas que levam os passageiros para um ponto de conexão, onde realizam o transbordo;

- Linhas Diretas: linhas que ligam um município a Goiânia sem parar em pontos de ônibus, parando somente em terminais; e

- Linhas Semiurbanas: linhas que realizam a ligação entre setores urbanos dos municípios não conurbados com o núcleo central da Região Metropolitana de Goiânia e os terminais de integração.

\section{Linhas de ônibus no município Goianira}

Como pode ser observado na Figura 4, houve expansão urbana entre 2010 e 2017 em Goianira. Isso propiciou o surgimento de novas linhas de ônibus: a quilometragem total das linhas que atendem o município cresceu em $35 \%$, aumentando de $155,9 \mathrm{~km}$, em 2010, para $210,3 \mathrm{~km}$, em 2017. A maior parte das novas linhas foi criada como linhas de conexão, para coletar ou levar passageiros dos bairros para a GO-070, onde existem pontos de conexão com a linha de ligação, a qual realiza o transporte de passageiros entre Goianira e Goiânia. 
Figura 4 - Linhas de ônibus em Goianira nos anos 2010 e 2017

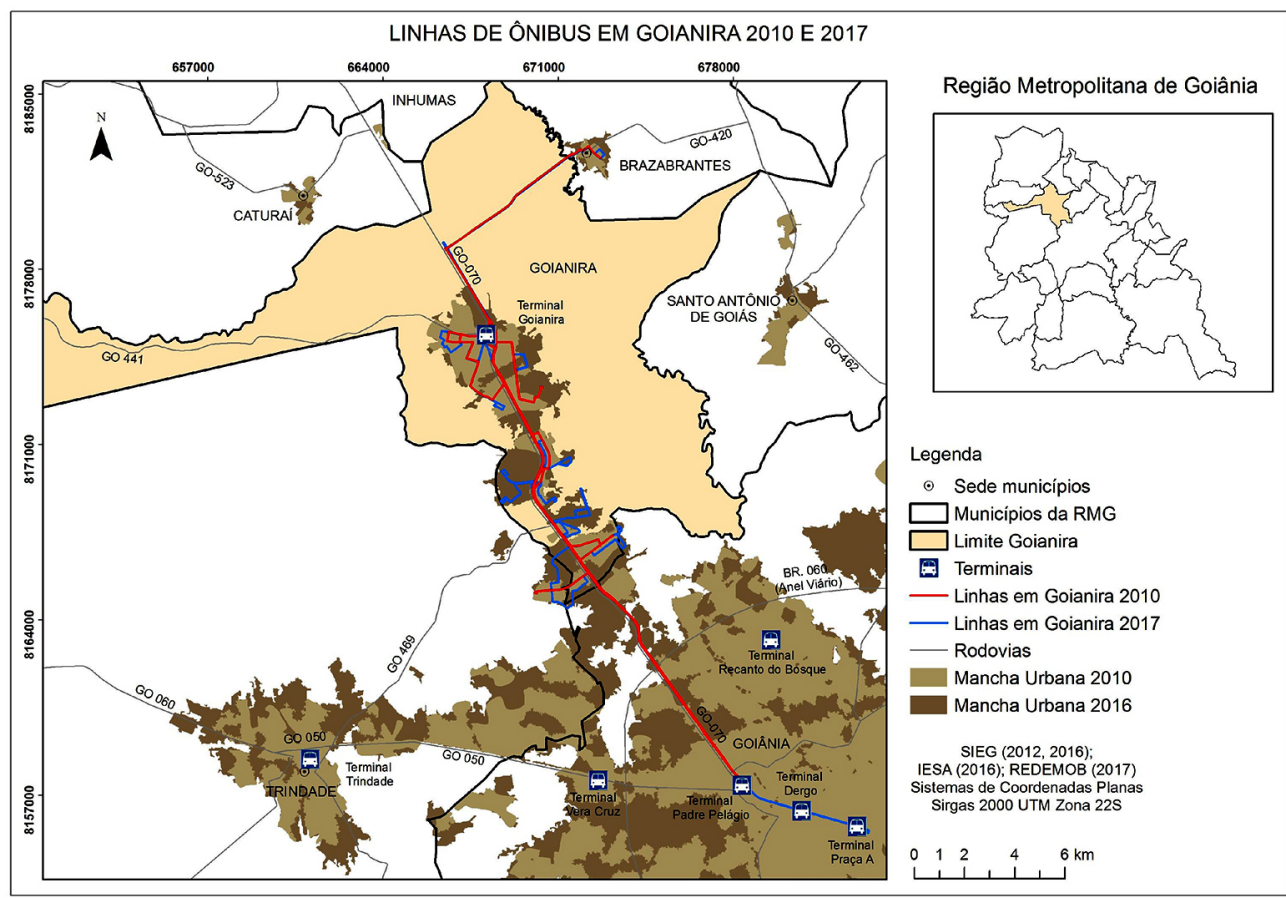

Fonte: Sieg (2016a, 2016b, 2017); lesa (2016); Redemob (2017). Elaborado pela autora.

Linhas de ônibus no município Senador Canedo

A mancha urbana de Senador Canedo também aumentou entre 2010 e 2016 . A quilometragem total das linhas teve um aumento de $34 \%$, crescendo de 299,9 km para 403,05 km. Como pode ser observado na Figura 5, parte das linhas que atendiam Senador Canedo em 2010 foi alterada para alcançar novas ocupações urbanas, e outras linhas também foram criadas por essa mesma razão.
Linhas de ônibus no município Trindade

Ao contrário do que ocorreu com os demais municípios analisados, em Trindade, o aumento da mancha urbana não foi acompanhado pelo aumento na quilometragem total das linhas entre 2010 e 2017 (Figura 6): em 2010 a quilometragem total das linhas era de 328,4 $\mathrm{km} \mathrm{e}$, em 2017, a quilometragem passou a ser de 290,3 km, o que caracteriza uma redução de $12 \%$ na quilometragem. Isso ocorreu em função de mudanças na configuração da rede 
Figura 5 - Linhas de ônibus em Senador Canedo nos anos 2010 e 2017

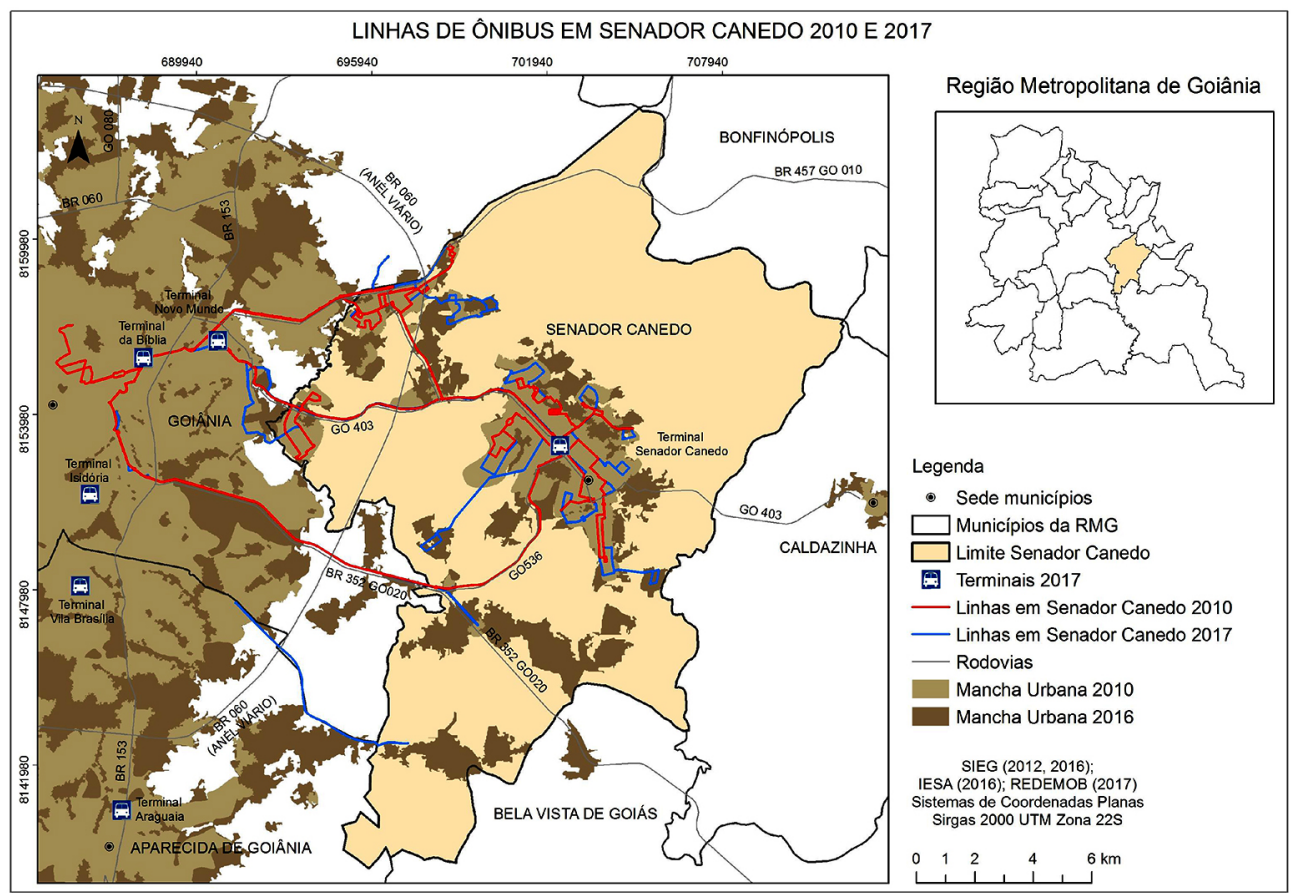

Fonte: Sieg (2016a, 2016b, 2017); lesa (2016); Redemob (2017). Elaborado pela autora.

de transportes para eliminar sobreposição de linhas e otimizar a rede. Ainda assim, parte das linhas que atendiam Trindade em 2010 foi alterada para alcançar ocupações urbanas mais distantes, e outras linhas alimentadoras surgiram pelo mesmo motivo, assim como as linhas de conexão que surgiram para atender à demanda na região nordeste do município.

Crescimento da mancha urbana e aumento da quilometragem

Em todos os municípios, com exceção de Trindade, a maior variação em números na quilometragem das linhas de ônibus aconteceu por meio das linhas alimentadoras ou linhas de conexão, pois estas são as linhas criadas ou expandidas para alcançar novas ocupações urbanas. Assim como o crescimento observado nas manchas urbanas, Goianira e Senador Canedo foram os municípios em que houve maior aumento de quilometragem nas linhas de ônibus. Em Goianira, foram acrescentados 68,2 km em linhas de ônibus de conexão para atender essas ocupações que surgiram entre 2010 e 2017. Em Senador Canedo, 44 km em linhas alimentadoras foram acrescentados também para atender ocupações urbanas que surgiram nesse intervalo de tempo. 
Figura 6 - Linhas de ônibus em Trindade nos anos 2010 e 2017

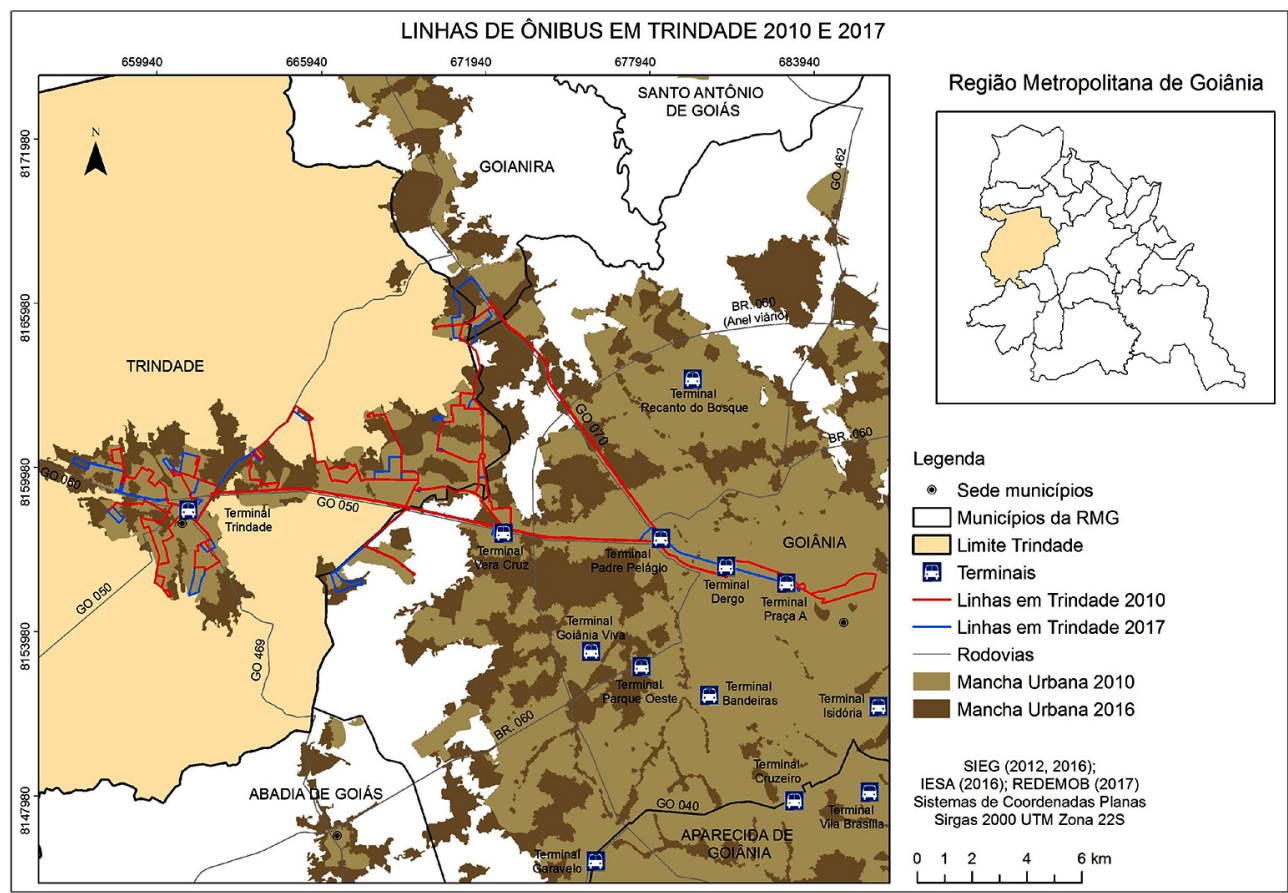

Fonte: Sieg (2016a, 2016b, 2017); lesa (2016); Redemob (2017). Elaborado pela autora.

Aplicação dos indicadores

e análise comparativa

\section{Intervalo de Viagem}

O Intervalo de Viagem corresponde ao tempo entre viagens de uma mesma linha. Esse indicador aumentou entre 2010 e 2017 para todos os municípios, o que alterou a qualidade de forma negativa para o usuário, como pode ser observado na Tabela 5. Em todos os municípios, as linhas que mais contribuíram para o aumento do Intervalo de Viagem foram as linhas alimentadoras e de conexão, que são as linhas que mais tiveram aumento em extensão, sem acréscimo na frota (valores da média de frota das linhas alimentadoras por município). Em Trindade, além do surgimento das linhas de conexão, houve redução de número de viagens e frota para as linhas alimentadoras, o que pode justificar o aumento no Intervalo de Viagem, já que não houve acréscimo de quilometragem em tais linhas. $O$ valor médio do Intervalo de Viagens em todos os municípios é considerado ruim ou regular tanto em 2010 quanto em 2017, segundo os padrões propostos por Ferraz e Torres (2004).

Em contrapartida, as médias dos valores de Intervalo de Viagem das linhas de ligação e semiurbanas são consideradas boas em todos os municípios, tanto em 2010, quanto 
Tabela 5 - Intervalo de Viagens por tipo de linhas nos anos 2010 e 2017

\begin{tabular}{|c|c|c|c|c|c|c|c|c|c|c|c|c|}
\hline \multirow{3}{*}{ Municípios } & \multicolumn{12}{|c|}{ Intervalo de Viagens (minutos) } \\
\hline & \multicolumn{2}{|c|}{$\begin{array}{c}\text { Ligação e } \\
\text { Semiurbana }\end{array}$} & \multicolumn{2}{|c|}{ Alimentadora } & \multicolumn{2}{|c|}{ Conexão } & \multicolumn{2}{|c|}{ Expressas } & \multicolumn{2}{|c|}{ Diretas } & \multicolumn{2}{|c|}{$\begin{array}{l}\text { Média do } \\
\text { Município }\end{array}$} \\
\hline & 2010 & 2017 & 2010 & 2017 & 2010 & 2017 & 2010 & 2017 & 2010 & 2017 & 2010 & 2017 \\
\hline Goianira & 7 & 6 & 28,75 & 33,19 & - & 40 & - & - & - & - & 24,5 & 33,51 \\
\hline Senador Canedo & 9,5 & 8,5 & 27,67 & 29,11 & - & 60 & 9 & 40 & - & 13 & 24 & 28,26 \\
\hline Trindade & 6 & 9 & 24,08 & 34 & - & 30 & 14 & - & - & - & 22,2 & 32,44 \\
\hline
\end{tabular}

Fonte: CMTC (2017). Elaborado e organizado pela autora.

em 2017. Como dito anteriormente, esses três municípios apresentam elevado número de pessoas que realizam deslocamento pendular para Goiânia; essa alta demanda justifica a necessidade de manter o Intervalo de Viagem baixo. Além disso, as linhas que fazem a ligação de Goiânia com Trindade, Senador Canedo e Goianira integram o Eixo Anhanguera desde 2015 e, em Senador Canedo, desde 2014, o que contribuiu para o aumento da demanda nessas linhas.

\section{Tempo de Viagem}

Com exceção de Senador Canedo, em que o Tempo de Viagem médio das linhas do município apresentou um aumento de $1 \%$ entre 2010 e 2017, nos outros dois municípios houve diminuição no Tempo de Viagem médio das linhas, o que é um fator positivo para o usuário, como pode ser observado na Tabela 6. Em Trindade e Goianira, a criação das linhas de conexão, as quais apresentam baixo tempo de viagem em função da baixa quilometragem que possuem, contribuiu de forma significativa para essa redução. Já em Senador Canedo, o aumento da extensão das linhas alimentadoras provocou aumento no Tempo de Viagem dessas linhas que, somados ao aumento das linhas de ligação, determinaram a variação positiva no tempo médio das viagens do município.

Tabela 6 - Tempo de Viagem por tipo de linhas nos anos 2010 e 2017

\begin{tabular}{|c|c|c|c|c|c|c|c|c|c|c|c|c|}
\hline \multirow{3}{*}{ Municípios } & \multicolumn{12}{|c|}{ Tempo de Viagem (minutos) } \\
\hline & \multicolumn{2}{|c|}{$\begin{array}{c}\text { Ligação e } \\
\text { Semiurbana }\end{array}$} & \multicolumn{2}{|c|}{ Alimentadora } & \multicolumn{2}{|c|}{ Conexão } & \multicolumn{2}{|c|}{ Expressas } & \multicolumn{2}{|c|}{ Diretas } & \multicolumn{2}{|c|}{$\begin{array}{l}\text { Média do } \\
\text { Município }\end{array}$} \\
\hline & 2010 & 2017 & 2010 & 2017 & 2010 & 2017 & 2010 & 2017 & 2010 & 2017 & 2010 & 2017 \\
\hline Goianira & 78 & 90 & 42,5 & 41 & - & 12,5 & - & - & - & - & 49,6 & 34,5 \\
\hline Senador Canedo & 66,5 & 82,5 & 35 & 38,43 & - & 30 & 87 & 57 & - & 30 & 42,67 & 43,16 \\
\hline Trindade & 66 & 90 & 43,69 & 35,4 & - & 18 & 120 & - & - & - & 50,27 & 38,81 \\
\hline
\end{tabular}

Fonte: CMTC (2017). Elaborado e organizado pela autora. 
Em Goianira, Trindade e Senador Canedo, as linhas de ligação ou semiurbanas apresentaram aumento no Tempo de Viagem. Nos três municípios, foi observado que esse aumento poderia estar relacionado a: a) a alteração dos ônibus que passaram a integrar o eixo Leste/Oeste e, por essa razão, passaram a ser articulados ao invés de convencionais, os quais demoram mais a fazer o percurso porque o ônibus articulado tem capacidade para 250 pessoas e é mais pesado, em contrapartida ao ônibus convencional que tem capacidade para 97 pessoas (CMTC, 2017); b) a alteração do início da viagem para outro terminal, aumentando a extensão da viagem, segundo dados da Redemob (2017); c) o aumento do congestionamento entre os municípios, já que, ao sair de Goiânia, tais ônibus não trafegam em corredores exclusivos.

\section{Índice de Passageiros por Quilômetro}

O IPK médio apresentado pelos municípios aumentou entre 2010 e 2017, como pode ser observado na Tabela 7. Contribuíram para esse aumento, nos três municípios, os valores apresentados pelas linhas de ligação e semiurbanas, nas quais houve aumento de demanda em função da alteração dessas linhas por linhas integrantes do eixo Leste-Oeste, no qual os usuários podem viajar pagando menos, já que recebem subsídio do governo (CMTC, 2017).

Em Goianira e Trindade, as linhas de conexão também contribuíram significantemente para o aumento do IPK, uma vez que essas linhas apresentam altos valores de intervalo entre viagens, o que possibilita menor número de viagens com maior concentração de passageiros em cada viagem e menores percursos, já que tais linhas são localizadas em pontos de conexão próximos às áreas de destino. Entretanto, nos dois anos analisados, os valores da média de cada município são inferiores a 2,5, valor mínimo considerado satisfatório para a eficiência do sistema, segundo Ferraz e Torres (2004).

\section{Índice de Passageiros por Veículo}

Os valores do Índice de Passageiros por Veículo apresentaram pequena variação positiva nas médias de Trindade, Goianira e Senador

Tabela 7 - Índice de Passageiros por Quilômetro por tipo de linhas nos anos 2010 e 2017

\begin{tabular}{|c|c|c|c|c|c|c|c|c|c|c|c|c|}
\hline \multirow{3}{*}{ Municípios } & \multicolumn{12}{|c|}{ Índice de Passageiros por Quilômetro } \\
\hline & \multicolumn{2}{|c|}{$\begin{array}{l}\text { Ligação e } \\
\text { Semiurbana }\end{array}$} & \multicolumn{2}{|c|}{ Alimentadora } & \multicolumn{2}{|c|}{ Conexão } & \multicolumn{2}{|c|}{ Expressas } & \multicolumn{2}{|c|}{ Diretas } & \multicolumn{2}{|c|}{$\begin{array}{l}\text { Média do } \\
\text { Município }\end{array}$} \\
\hline & 2010 & 2017 & 2010 & 2017 & 2010 & 2017 & 2010 & 2017 & 2010 & 2017 & 2010 & 2017 \\
\hline Goianira & 1,25 & 1,31 & 2,31 & 1,59 & - & 2,52 & -- & - & - & - & 2,05 & 2,07 \\
\hline Senador Canedo & 0,86 & 1,06 & 1,6 & 1,64 & - & 1,52 & 1,67 & 1,82 & - & 3,38 & 1,5 & 1,67 \\
\hline Trindade & 0,72 & 1,03 & 1,34 & 1,35 & - & 1,58 & 1,84 & - & - & - & 1,33 & 1,36 \\
\hline
\end{tabular}

Fonte: CMTC (2017). Elaborado e organizado pela autora. 
Canedo, como apresentado na Tabela 8. No entanto, em nenhum município esse índice alcançou valores satisfatórios para a eficiência do sistema, conforme proposto por Ferraz e Torres (ibid.). Em Trindade e Goianira, as linhas que contribuíram para o aumento no Índice de Passageiros por Veículo foram as linhas de conexão existentes em 2017 e que, além de apresentarem maiores intervalos de viagem, também apresentam valores baixos de frota (entre 1 e 3 veículos). Em Senador Canedo, o aumento na média aconteceu por meio da linha direta 111, que funciona apenas em horário de pico e não possui paradas intermediárias, de forma que atrai usuários e concentra maior número de passageiros em cada viagem.

É preciso destacar o fato de que os valores de IPK e Índice de Passageiros por Veículo nas linhas de ligação e semiurbanas permanecem baixos em Trindade, Goianira e Senador Canedo mesmo com o aumento da demanda, advindo da integralização de tais linhas ao eixo Leste-Oeste. A partir dessa constatação, é possível inferir que a quilometragem excessiva, aliada a deslocamentos pendulares e polaridade entre municípios, é prejudicial ao sistema de transporte coletivo. Também é importante o fato de que, enquanto grandes distâncias e deslocamentos pendulares influenciam na baixa rotatividade dos passageiros nas linhas de ligação e semiurbanas, nas demais linhas, com exceção das linhas diretas, o que se percebe prejudicial é a baixa quantidade de passageiros que as utilizam, provavelmente em função de uma ocupação urbana de baixa densidade, espraiada no território.

Outra constatação importante está relacionada às linhas de conexão. Enquanto os valores de Intervalo de Atendimento apresentados por essas linhas são considerados negativos e alteram a qualidade do sistema para o usuário de forma negativa, os valores que indicam a eficiência do sistema dessas mesmas linhas alteram a média do município de forma positiva, ou seja, contribuem para o aumento nos valores do Índice de Passageiros por Quilômetro e Índice de Passageiros por Veículo.

Tabela 8 - Índice de Passageiros por Veículo por tipo de linhas nos anos 2010 e 2017

\begin{tabular}{|c|c|c|c|c|c|c|c|c|c|c|c|c|}
\hline \multirow{3}{*}{ Municípios } & \multicolumn{12}{|c|}{ Índice de Passageiros por Veículo } \\
\hline & \multicolumn{2}{|c|}{$\begin{array}{c}\text { Ligação e } \\
\text { Semiurbana }\end{array}$} & \multicolumn{2}{|c|}{ Alimentadora } & \multicolumn{2}{|c|}{ Conexão } & \multicolumn{2}{|c|}{ Expressas } & \multicolumn{2}{|c|}{ Diretas } & \multicolumn{2}{|c|}{$\begin{array}{l}\text { Média do } \\
\text { Município }\end{array}$} \\
\hline & 2010 & 2017 & 2010 & 2017 & 2010 & 2017 & 2010 & 2017 & 2010 & 2017 & 2010 & 2017 \\
\hline Goianira & 183,42 & 148,88 & 180,53 & 95,19 & - & 240,58 & -- & - & - & - & 181,25 & 188,79 \\
\hline Senador Canedo & 136,89 & 119,92 & 146,28 & 130,99 & - & 116 & 88,06 & 91,2 & - & 278,8 & 141,15 & 141,98 \\
\hline Trindade & 108 & 104,02 & 148,29 & 118,35 & - & 357,5 & 99,6 & - & - & - & 142,36 & 144,12 \\
\hline
\end{tabular}

Fonte: CMTC (2017). Elaborado e organizado pela autora. 


\section{Impactos do espraiamento urbano e das relações metropolitanas no sistema de transporte coletivo}

A partir das análises realizadas, algumas conclusões serão elencadas a seguir:

- existe relação entre a expansão territorial das ocupações urbanas e a quilometragem de viagens total das linhas de ônibus em cada município da RMG: o aumento da mancha urbana é acompanhado pela extensão das linhas de ônibus.

- A qualidade do serviço oferecida ao usuário é prejudicada pela expansão urbana de baixa densidade, principalmente por meio da diminuição na frequência de viagens, com aumento no Intervalo de Viagem. Isso acontece nas linhas alimentadoras e de conexão em função da baixa densidade de passageiros e do aumento nos percursos.

- A qualidade oferecida ao usuário também é prejudicada pelo aumento no Tempo de Viagem das linhas semiurbanas ou de ligação, as quais realizam a ligação entre Goiânia e o município do entorno.

- A eficiência do sistema de transporte coletivo é prejudicada pela baixa rotatividade de passageiros nos deslocamentos entre os municípios do entorno e o município-polo da RMG assim como também pela baixa densidade de passageiros que circulam dentro do próprio município periférico.

- Algumas estratégias operacionais possibilitam pequenas melhoras nos índices de eficiência, porém alteram de forma negativa a qualidade do sistema para o usuário: linhas de conexão são criadas para recolher passageiros em pontos de conexão situados em pontos estratégicos para a distribuição de passageiros nos bairros, mas funcionam com altos intervalos de viagem; modos operacionais ou sublinhas são criados para atender novas ocupações urbanas, mas em alguns casos tais modos funcionam em horários específicos, com Intervalos de Viagem superiores a uma hora.

Dessa forma, a partir das conclusões elencadas, é possível compreender que os impactos sociais relacionados à polaridade entre os municípios periféricos e Goiânia, na medida em que propicia os deslocamentos pendulares, relacionam-se aos tempos excessivos de viagem aos quais os usuários são submetidos ao recorrerem às viagens intermunicipais destinadas ao município-polo. 0 espraiamento urbano nas regiões periféricas, diretamente relacionado à polarização metropolitana, também provoca impactos sociais no sistema de transporte coletivo da Região Metropolitana de Goiânia que, aferidos por meio de índices de qualidade aplicados a municípios selecionados, estão relacionados à baixa frequência de viagens das linhas que realizam a distribuição dos usuários dentro do município periférico.

Os impactos econômicos relacionados às viagens com destino à Goiânia, fruto das relações metropolitanas estabelecidas, aferidos por meio de índices de eficiência aplicados a municípios selecionados, afetam negativamente o sistema porque não permitem a rotatividade de passageiros nos veículos. A consequente dispersão urbana nos municípios periféricos também provoca impactos econômicos no sistema de transporte coletivo da Região Metropolitana de Goiânia, impactos estes que se relacionam à baixa demanda de passageiros que circulam dentro do próprio município periférico. 


\section{Considerações finais}

A Rede Metropolitana de Transportes Coletivos de Goiânia (RMTC), unificada e integrada, permite a transferência de passageiros entre linhas na região central de cada município e entre municípios, aumentando de forma considerável a área de atendimento do transporte coletivo na RMG. Ao permitir as conexões entre municípios, a RMTC contribui para a acessibilidade da população residente nos municípios periféricos da RMG aos serviços que se concentram em Goiânia: trabalho, estudo, saúde, lazer.

No entanto, mesmo com alterações na rede, o transporte coletivo na RMG não alcança níveis satisfatórios de eficiência para o sistema e qualidade para o usuário, de forma que está sempre "correndo atrás do prejuízo" em função de uma forma de ocupação urbana espraiada, com baixa densidade de passageiros nos municípios periféricos e da baixa rotatividade de passageiros nas linhas que fazem as conexões desses municípios com Goiânia.

É necessário propiciar o policentrismo e a melhor distribuição de serviços, assim como também tornar os municípios periféricos mais independentes do município-polo, fortalecendo a economia desses municípios, de modo que a maior parte da população possa trabaIhar e estudar no município onde reside, diminuindo, assim, os deslocamentos pendulares.

Então, é preciso evitar que a gestão ou mesmo as políticas públicas continuem reforçando o modelo centro-periferia de expansão das cidades, principalmente a partir da aprovação de novos loteamentos em áreas periféricas desses municípios, distantes dos locais de trabalho e de estudo. A efetividade dessa medida depende de políticas que tornem as centralidades existentes nos municípios da RMG, assim como da capital, mais acessíveis à população de baixa renda. Para tanto, é necessário que a escala de planejamento urbano seja ampliada para a região metropolitana, conforme designação do Estatuto da Metrópole (Brasil, 2015) e que tal planejamento seja compatível com os planos de mobilidades locais, de forma que seja possível limitar a expansão urbana e propiciar o crescimento urbano em regiões em que este não cause impactos econômicos, ambientais e sociais.

Ao mesmo tempo, o fortalecimento local da economia pode favorecer o transporte coletivo e o uso de modais não motorizados dentro dos próprios municípios. A integração entre o planejamento do uso, a ocupação do solo e o transporte coletivo em cada munícipio periférico pode tornar as viagens mais eficientes e sustentáveis. As rotas das linhas alimentadoras e de conexão, uma vez que distribuem os passageiros nos bairros desses municípios, devem ser planejadas em conjunto com as políticas de ocupação do solo, locadas em percursos que contemplem regiões destinadas ao adensamento. As políticas de uso do solo, por sua vez, devem propiciar o adensamento de forma diversificada, admitindo e favorecendo a convivência entre atividades distintas, as quais possibilitam a rotatividade de passageiros mesmo entre as diversas centralidades de cada município.

Maior diversidade de atividades e serviços nos bairros também estimula deslocamentos mais curtos, por meio de modais mais sustentáveis, como caminhadas e bicicletas. Nesse sentido, é preciso que haja investimento em infraestruturas direcionadas ao pedestre e ao ciclista, integradas ao transporte 
coletivo. A priorização do uso de modos não motorizados, por meio de calçadas adequadas, ciclofaixas, ciclovias e segurança, além de evitar o aumento das rotas do transporte coletivo para regiões afastadas e pouco densas, também potencializa esse transporte, concentrando o número de passageiros nos terminais de cada município.

O procedimento metodológico proposto neste trabalho se mostrou adequado para o registro e a identificação do processo investigado e pode ser aplicado a qualquer região metropolitana, desde que os indicadores selecionados possam mostrar corretamente a relação entre a região de estudo escolhida e os aspectos investigados sobre o transporte coletivo.

A importância deste trabalho consiste em contribuir para o entendimento de que as possibilidades criadas pelo Estatuto das Metrópoles para a gestão compartilhada do território em regiões metropolitanas devem ser aplicadas na Região Metropolitana de Goiânia de forma emergencial. 0 transporte coletivo na RM aponta há anos, principalmente por meio da percepção dos usuários e da efetiva queda na demanda (CMTC, 2017), a necessidade de aliar seu planejamento à utilização e à ocupação do solo, de forma que seja possível sua otimização. No âmbito municipal, este trabalho pode contribuir com planos diretores municipais ou de mobilidade urbana, fortalecendo a necessidade de alinhar esses planos aos planos metropolitanos e fornecendo subsídios para isto.

A principal dificuldade encontrada na realização deste trabalho está vinculada à obtenção de dados que, no Brasil, são produzidos em longos intervalos temporais, como aqueles vinculados ao censo demográfico, realizado a cada dez anos. Esse intervalo temporal dificulta o entendimento das relações inerentes à população e ao território, uma vez que estas são mais dinâmicas. A aquisição de dados relacionados à ocupação do território também é difícil, principalmente quando se trata de número de habitações nos municípios periféricos e também na capital, tão necessário para identificar a forma de crescimento urbano de uma região.

$\mathrm{Na}$ área de transportes, a inexistência de uma pesquisa origem e destino mais recente para caracterizar os deslocamentos na Região Metropolitana de Goiânia é a principal dificuldade. Para suprir essa deficiência, foram necessárias a utilização dos fluxos pendulares publicados pelo IBGE (2016) referentes ao ano de 2010 e a utilização de dados da demanda do sistema de transporte coletivo na RMG em 2010 e 2017, fornecidos pela CMTC (2017) e Redemob (2017). Ainda assim, como demonstrado por esta pesquisa, é possível caracterizar o sistema de transporte coletivo de uma região e compreender como este se relaciona com as dinâmicas metropolitanas. 


\section{[I] https://orcid.org/0000-0003-0249-7412}

Universidade de Brasília, Faculdade de Arquitetura e Urbanismo, Programa de Pós-Graduação em Arquitetura e Urbanismo. Brasília, DF/Brasil.

anacfernandes.arq@gmail.com

\section{[II] https://orcid.org/0000-0003-3342-5198}

Universidade Federal de Goiás, Curso de Arquitetura e Urbanismo, Programa de Pós-Graduação em Projeto e Cidade. Goiânia, GO/Brasil.

erikakneib@ufg.br

\section{[III] https://orcid.org/0000-0002-2679-5812}

Universidade de Brasília, Faculdade de Planaltina, Programa de Pós-Graduação em Arquitetura e Urbanismo. Brasília, DF/Brasil.

Observatório das Metrópoles, núcleo Brasília. Brasília, DF/Brasil.

rjcribeiro@gmail.com

\section{Referências}

BALBIM, R. (2016). "Mobilidade: uma abordagem sistêmica”. In: BALBIM, R; KRAUSE, C.; LINKE, C. C. (orgs.). Cidade e movimento: mobilidades e interações no desenvolvimento urbano. Brasília, Ipea e IDTP.

BARBOSA, J. L. (2016). "O significado da mobilidade na construção democrática da cidade". In: BALBIM, R; KRAUSE, C.; LINKE, C. C. (orgs.). Cidade e movimento: mobilidades e interações no desenvolvimento urbano. Brasília, Ipea e IDTP.

BITOUN, J.; SOUZA, M. A. de A. (2015). Recife: transformações na ordem urbana. Rio de Janeiro, Letra Capital.

BRASIL (2012). Diário Oficial da República Federativa do Brasil. Brasília, DF.

(2015). Diário Oficial da República Federativa do Brasil. Brasília, DF.

CMTC - COMPANHIA METROPOLITANA DE TRANSPORTES COLETIVOS (2013). Informações sobre a RMTC. Disponível em: http://www.sgc.goias.gov.br/upload/arquivos/2013-06/3.1-informacoessobre-a-rmtc.pdf. Acesso em: jun 2017.

(2017). Relatório e Banco de dados do sistema de transporte coletivo da Rede Metropolitana de Transporte Coletivo - RMTC 2017. Goiânia, CMTC.

CUNHA, J. M. P. (2006). "Introdução". In: CUNHA, J. M. P. (org.). Novas Metrópoles Paulistas: população, vulnerabilidade e segregação. Vulnerabilidade, pp. 11-20. Disponível em: https://www.nepo. unicamp.br/publicacoes/livros/vulnerabilidade/index.htm. Acesso em: jun 2019.

DELGADO, P. R. et al. (2016). “Mobilidades nas regiões metropolitanas brasileiras: processos migratórios e deslocamentos pendulares". In: BALBIM, R; KRAUSE, C.; LINKE, C. C. (orgs.). Cidade e movimento: mobilidades e interações no desenvolvimento urbano. Brasília, Ipea/IDTP. 
FERRAZ, A. C. C. P.; TORRES, I. G. E. (2004). Transporte público urbano. São Carlos, Rima.

GOIÁS (2000). Diário Oficial do Estado de Goiás. Goiânia, GO.

(2010). Diário Oficial do Estado de Goiás. Goiânia, GO.

IBGE - INSTITUTO BRASILEIRO DE GEOGRAFIA E ESTATÍ́STICA (2010). Censo demográfico 2010. Rio de Janeiro, IBGE.

(2016). Arranjos populacionais e concentrações urbanas do Brasil. Disponível em: http://www. ibge.gov.br/home/geociencias/geografia/geografia_urbana/arranjos_populacionais/default. shtm?c=9. Acesso em: mar 2017.

(2017). Estimativas da população residente no Brasil e unidades da federação com data de referência em 1을 de julho de 2017. Disponível em: https://www.ibge.gov.br/estatisticasnovoportal/sociais/populacao/9103-estimativas-de-populacao.html?=\&t=downloads. Acesso em: abr 2018.

IESA - INSTITUTO DE ESTUDOS SOCIOAMBIENTAIS (2016). Mancha urbana da Região Metropolitana de Goiânia em 2016.

IMB - INSTITUTO MAURO BORGES DE ESTATÍsTICAS E ESTUdOS SOCIOECONÔMICOS (2012). Mobilidade pendular da população em Goiás. Goiânia, IMB.

(2017). Perfil dos municípios goianos. Disponível em: http://www.imb.go.gov.br/. Acesso em: jun 2017.

IPEA - INSTITUTO DE PESQUISA ECONÔMICA APLICADA (2010). Infraestrutura social e urbana no Brasil: subsídios para uma agenda de pesquisa e formulação de políticas públicas. Livro 6, vol. 2. Brasília, Ipea.

(2016). "Introdução". In: BALBIM. R; KRAUSE C.; LINKE C. C. (orgs.). Cidade e movimento: mobilidades e interações no desenvolvimento urbano. Brasília, Ipea e IDTP.

MATTOS, C. de (2004). "Redes, nodos e cidades: transformação da metrópole latino-americana". In: RIBEIRO, L. C. Q. (org.). Metrópoles: entre a coesão e a fragmentação, a cooperação e o conflito. São Paulo, Editora da Fundação Perseu Abramo; Rio de Janeiro, Fase.

MINISTÉRIO DAS CIDADES (2015). PlanMob: construindo a cidade sustentável - Caderno de referência para elaboração de plano de mobilidade urbana. Brasília, Ministério das Cidades.

MINISTÉRIO DO TRABALHO (2017). Relação Anual de Informações Sociais - Rais: ano base 2016 Goiás. Disponível em: http://pdet.mte.gov.br/rais?view=default. Acesso em: 14 jun 2017.

NTU - ASSOCIAÇÃO NACIONAL DAS EMPRESAS DE TRANSPORTES URBANOS (2008). Desempenho e qualidade nos sistemas de ônibus urbanos. São Paulo, NTU.

PNUD-PROGRAMA DAS NAÇÕES UNIDAS PARA O DESENVOLVIMENTO (2014). Atlas do desenvolvimento humano nas Regiões Metropolitanas Brasileiras. Brasil, PNUD.

ROGERS, R. G.; GUMUCHDJIAN, P. (2005). Cidades para um pequeno planeta. Barcelona, Gustavo Gili.

REDE INTEGRADA DE TRANSPORTE COLETIVO (2017). Informações Institucionais. Disponível em: http:// www.rmtcgoiania.com.br/sobrea-a-rmtc/informacoes-institucionais. Acesso em: jun 2017.

REDEMOB (2017). Banco de dados do sistema de transporte coletivo da Rede Metropolitana de Transporte Coletivo - RMTC 2017. Goiânia, Redemob. 
RMTC (2017). Informações institucionais. Disponível em: http://www.rmtcgoiania.com.br/sobrea-armtc/informacoes-institucionais. Acesso em: jun 2017.

SIEG - SISTEMA ESTADUAL DE GEOINFORMAÇÃO (2016a). Mapeamento das manchas urbanas do ano de 2000 dos 20 municípios da Região Metropolitana de Goiânia. Sieg. Disponível em: http://www. sieg.go.gov.br/produtosIMB.asp?cod=4093. Acesso em: maio 2018.

(2016b). Mapeamento das manchas urbanas do ano de 2010 dos 20 municípios da Região Metropolitana de Goiânia. Sieg. Disponível em: http://www2.sieg.go.gov.br/post/ver/209735/ manchas-urbanas-da-rmg. Acesso em: maio 2017.

(2017). Municípios 2017. Sieg. Disponível em: http://www.sieg.go.gov.br/produtosIMB. asp?cod=4627. Acesso em: maio 2018.

UFG - UNIVERSIDADE FEDERAL DE GOIÁS (2017). Plano de desenvolvimento urbano integrado da Região Metropolitana de Goiânia. Goiânia, UFG.

UNITED NATIONS (2015). World Urbanization Prospects - The 2014 Revision. Nova York, Department of Economic and Social Affairs.

TRANSPORTATION RESEARCH BOARD (2013). Transit capacity and quality of service manual. Washington, D.C., Transit Cooperative Research Program.

VILLAÇA, F. A. (1997). Delimitação territorial do processo urbano. Disponível em: http://www. flaviovillaca.arq.br/pdf/intra497.pdf. Acesso em: maio 2017.

VUCHIC. V. R. (2004). Urban transit: operations planning and economics. Wiley.

Texto recebido em 16/jun/2019

Texto aprovado em 24/ago/2019 